\title{
Maxillofacial rehabilitation of adenoid cystic carcinoma patient using full mouth fixed implant and pharyngeal obturator: a clinical report
}

\author{
Min-Hee Ban, Hong-So Yang, Sang-Won Park, Hyun-Pil Lim*, Kwi-Dug Yun, Chan Park, Jin-Ho Shin \\ Department of Prosthodontics, School of Dentistry, Chonnam National University, Gwangju, Republic of Korea
}

Rehabilitation of maxillectomy patients is challenging. The maxillary defects need to functional restoration because of mastication, speech, swallowing problems. The goal of making obturator is to restore maxillary defects and give patients comfortable, esthetic prosthesis. This case report presents acquired masticatory and esthetic results and improved retention resulting from the pharyngeal obturator prosthesis using implant. (J Dent Rehabil Appl Sci 2016;32(4):351-7)

Key words: adenoid cystic carcinoma; maxillectomy; pharyngeal obturator; CAD/CAM

\begin{abstract}
서론
선양낭포암(Adenoid cystic carcinoma)은 주로 침샘에 발생하는 드문 암으로 대부분 이하선, 악하선, 소타액선 에서 발생하고 소타액선의 경우 구개, 혀, 협측점막, 입술 과 구강저 순으로 주로 발생한다. 가장 흔한 증상은 암세 포의 신경주위 침입(Perineural invasion)의 경향으로 인 하여 종물은 통증과 함께 느리게 성장한다. 선양낭포암 을 치료하는 첫번째 옵션으로는 신체 부위에 상관 없이 수술적으로 명확한 경계를 가지고 절제하는 것이다. ${ }^{1}$

상악절제술(Maxillectomy)은 대부분 구개부위에 결손 부를 남기고 구강과 비강 및 인두의 정상기능에 영향을 미친다. 악안면 보철치료로 폐쇄장치(Obturator)를 통하 여 구개의 결손부를 대체하고 구강과 비강 사이를 폐쇄 하여 구강과 비강을 분리할 수 있다. 연구개의 정상 기능 은 구강과 비강을 분리하며 발음, 연하, 호흡시 생리적 요 구에 따라 운동하게 되고 연구개와 인두벽간의 폐쇄를 담당한다. 폐쇄장치의 기능은 비강으로 음식이나 액체
\end{abstract}

*Correspondence to: Hyun-Pil Lim

Associate Professor, Department of Prosthodontics, School of Dentistry, Chonnam National University, 33 Yongbong-ro, Buk-gu, Gwangju, 61186, Republic of Korea

Tel: +82-62-530-5577, Fax: +82-62-530-5639, E-mail: mcnihil@jnu.ac.kr Received: September 29, 2016/Last Revision: December 12, 2016/Accepted: December 19, 2016
등이 새는 것을 막고 발음의 정확도를 향상시킬 수 있다. 또한 결손부위에 적절한 부피와 무게를 부여하여 저작, 발음, 연하, 그리고 심미와 같은 구강의 기능을 회복 할 수 있다. ${ }^{2}$

폐쇄장치는 가철성 의치의 지지, 유지, 안정의 원리를 기 본으로 제작되어야 한다. 잔존 자연치, 잔존 치조제, 경구 개, 잔존 연구개 등이 기여하게 되고, 치아가 모두 발거된 다면 임플란트 식립을 통하여 자연치의 역할을 대신할 수 있다. ${ }^{3,4}$ 인두폐쇄장치(Pharyngeal obturator)는 임플란트 를 이용한 서베이드 금관을 제작하여 폐쇄장치의 전방부 는 가철성 국소의치의 형태를 따르고 연결부를 통하여 결 손부를 대체하는 인두부와 연결되는 형태로 제작하였다.

본 증례는 선양낭포암으로 인하여 좌측 상악골 절제술 을 받은 환자를 인두폐쇄장치로 결손부를 수복하였다. 상 악의 잔존치를 모두 발거 하였기 때문에 다수의 임플란트 를 식립하여 장치의 유지부를 설계하고 인두폐쇄장치로 결손부를 수복하였다. 고정성 임플란트 보철물을 통하여 심미적 부분에서 상당한 개선이 이루어 졌으며, 기능적으

Copyright@ 2016 The Korean Academy of Stomatognathic Function and Occlusion. (c) It is identical to Creative Commons Non-Commercial License. 
로도 만족할 만한 결과를 얻어 이를 보고하고자 한다.

\section{증례 보고}

본 증례환자는 57 세 남자환자로 본원 구강악안면외 과에서 좌측 연구개측에 선양낭포암(Adenoid cystic carcinoma, stage III: pT2N1M0)으로 진단받은 후 좌측 후방부위에 부분적인 상악골 절제수술을 받고 본원 보철 과에 내원하였다(Fig. 1). 구강 내 검사 및 방사선학적 검 사에서 하악은 비교적 건전하였으며 상악에 다수의 상실 치아와 함께 잔존치인 \#13,14, 23, 24, 25는 치은연하 우 식 및 불량한 치관 대 치근비를 보였다(Fig. 2, 3). 또한 환 자는 좌측 연구개 부위가 절제되어 구강과 인두 사이가 개방되어 있어 물은 물론 음식을 삼키기도 어려워 식사도 불가한 상태였다. 비강으로 음식이나 액체 등이 새는 것 을 막기 위하여 임시 인두 폐쇄장치의 제작이 필요하였다.

처음에는 임플란트 지지 피개의치로 상악골 재건이 고 려되었으나, 환자가 의치 형식 보다는 저작력이 더 뛰어 난 고정성 보철물을 원하였고, 남아있는 잔존 치아들도 예후가 좋지 않아 모두 발거 하였다. 잔존치 발거 후에는
임시 인두 폐쇄장치를 제작하였다. 상악에 \#12i, $13 \mathrm{i}, 14 \mathrm{i}$, $16 \mathrm{i}, 22 \mathrm{i}, 23 \mathrm{i}, 24 \mathrm{i}, 26 \mathrm{i}$, 총 8개의 임플란트 식립하였다. 골 폭에 따라 우측 측절치와 견치는 직경이 적은 임플란트 (USll SA Fixture, $3.3 \times 13 \mathrm{~mm}$, Osstem implant, Busan, Korea)를 식립하였고, 좌측 측절치와 견치는 우측보다 는 직경이 큰 임플란트(USll SA Fixture, $3.75 \times 13 \mathrm{~mm}$, Osstem implant)를 식립하였고, 나머지 치아들은 동일 한 회사의 $4 \mathrm{~mm}$ 직경의 임플란트(US1l SA Fixture, 4.0 $\times 11.5 \mathrm{~mm}$, Osstem implant)를 식립하였다(Fig. 4). 임 플란트 식립 4 개월 후, 구개 회전 피판을 이용한 구강상 악동루 폐쇄술(closure of Oroantral Fistula with palatal rotation flap)을 시행하였고, 6 개월 후에는 지대주와 임 시 크라운을 computer aided design/computer aided manufacturing $(\mathrm{CAD} / \mathrm{CAM})$ 밀링을 이용하여 제작하였 다. 최종적인 인두 폐쇄장치 제작에 앞서, 임시 크라운을 지대치로 하여 2 차 임시 obturator를 제작하였다. 3 개월 이 지난 후 임시보철물의 적응된 교합상태를 그대로 이 전하기 위해 안궁이전을 통한 cross-mounting을 이용하 여 $\mathrm{CAD} / \mathrm{CAM}$ 으로 제작한 지르코니아 서베이드 크라 운을 최종 합착하였다(Fig. 5, 6).
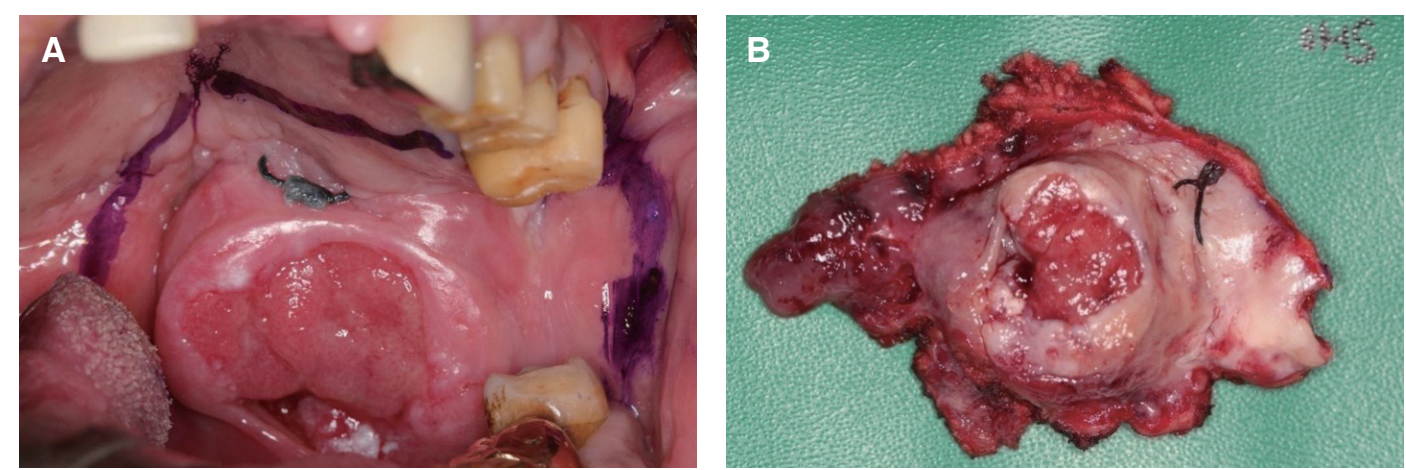

Fig. 1. Intraoral photograph. Adenoid cystic carcinoma, stage III: pT2N1M0. (A) Pre-operative view, (B) Resected mass view.

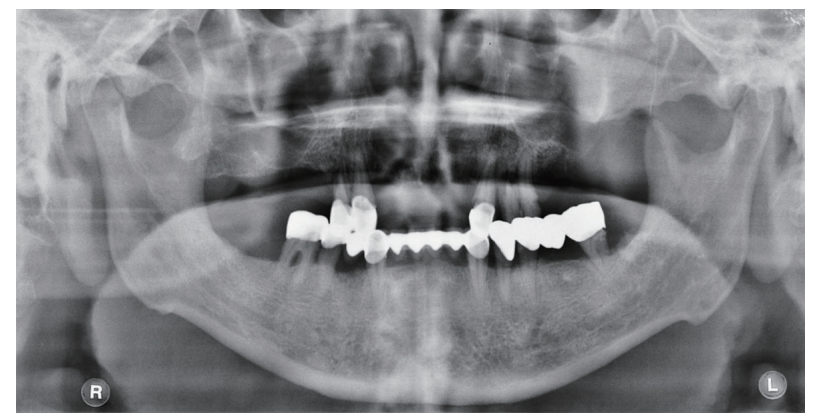

Fig. 2. Initial panoramic radiograph. 

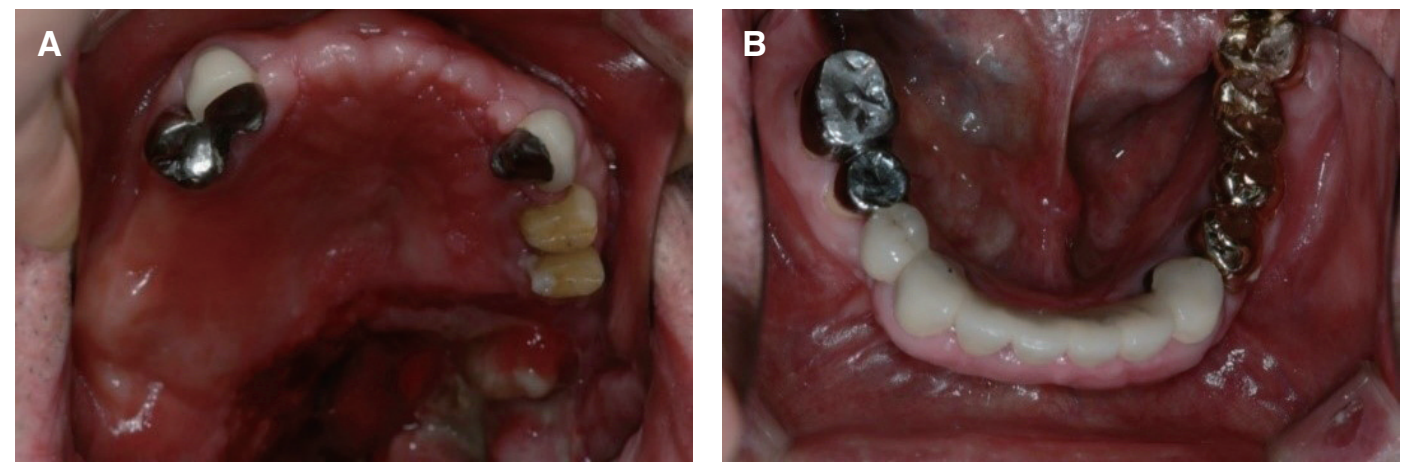

Fig. 3. Initial intraoral photographs. (A) Maxillary occlusal view, (B) Mandibular occlusal view.

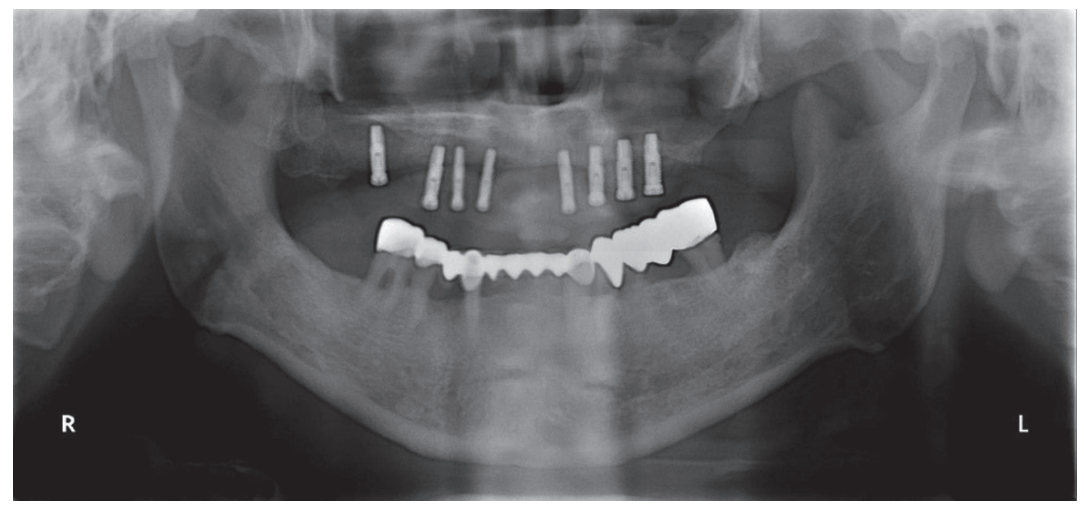

Fig. 4. Panoramic radiograph after implant installation.
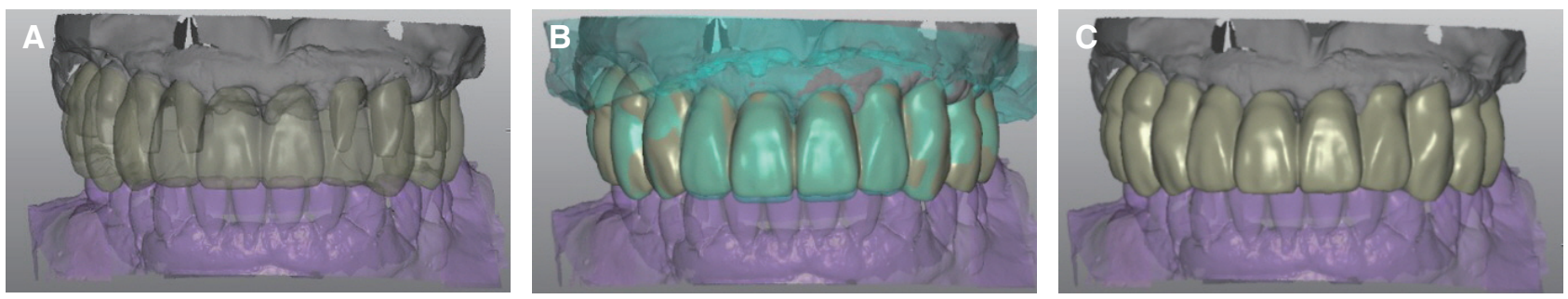

Fig. 5. Double scanning technique for definitive prosthesis. (A) Abutment with provisional restoration scanning, (B) Superimposion, (C) Final restoration.
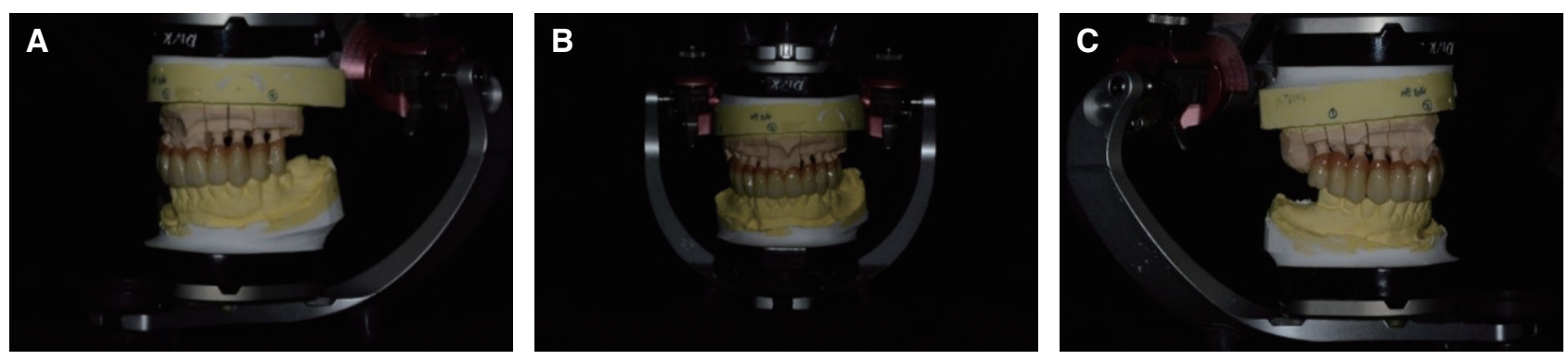

Fig. 6. CAD/CAM full contour monolithic zirconia surveyed crown. (A) Right lateral view, (B) Frontal view, (C) Left lateral view. 
최종적으로 지르코니아 보철물이 시적 된 후에 최종 인두 폐쇄장치의 제작이 시작되었다. 통상적인 방법으 로 개인트레이를 제작하였다. 구강 내에서 기능인상을 후 실리콘인상재(Exadenture, GC, Tokyo, Japan)를 이 용하여 인상을 채득하였다. 금속프레임은 장치의 파절 가능성을 줄이기 위해 구개부와 인두부를 연결하는 부 위를 약간 넓게 제작하였다. 결손부 정밀 인상 채득을 위해 금속프레임을 트레이로 사용해 케 타입 컴파운드 (Impression Compound, Kerr, Salerno, Italy)를 이용하 여 인두부위의 인상을 채득하였다(Fig. 7). 환자의 턱이 가슴에 닿도록 몸을 완전히 구부리게 하여 폐쇄장치의 후방면의 접촉을 이루게 하고, 턱을 오른쪽과 왼쪽 어깨
에 닿도록 목을 구부리게 하여 폐쇄장치의 측방을 형성 하였다(Fig. 8). 또한 컴파운드를 연화시킨 후 따뜻한 물 을 삼키게 하여 인두근육을 활성화시켰다. 변연형성이 완 성된 후에는 물을 삼켰을 때 비강으로 새지 않는 것을 확 인하고 b, p 같은 파열음과 $\mathrm{m}, \mathrm{n}, \mathrm{ng}$ 같은 비음을 낼 수 있는 것을 확인하였다. ${ }^{5}$ 최종적으로 모든 변연의 컴파운 드를 균일하게 삭제 한 후에 목의 운동을 반복하여 기능 시 근육의 움직임을 기록하기 위하여 점막조정제 $(\mathrm{Coe}-$ comfort, GC America Inc., Alsip, USA)를 이용하여 인 상을 채득하였다. 인상채득 후 안정성을 위해 24시간 후 제작하였다. 이를 통하여 임플란트를 이용한 서베이드 금관으로부터 얻은 유지, 지지력을 이용한 인두 폐쇄장
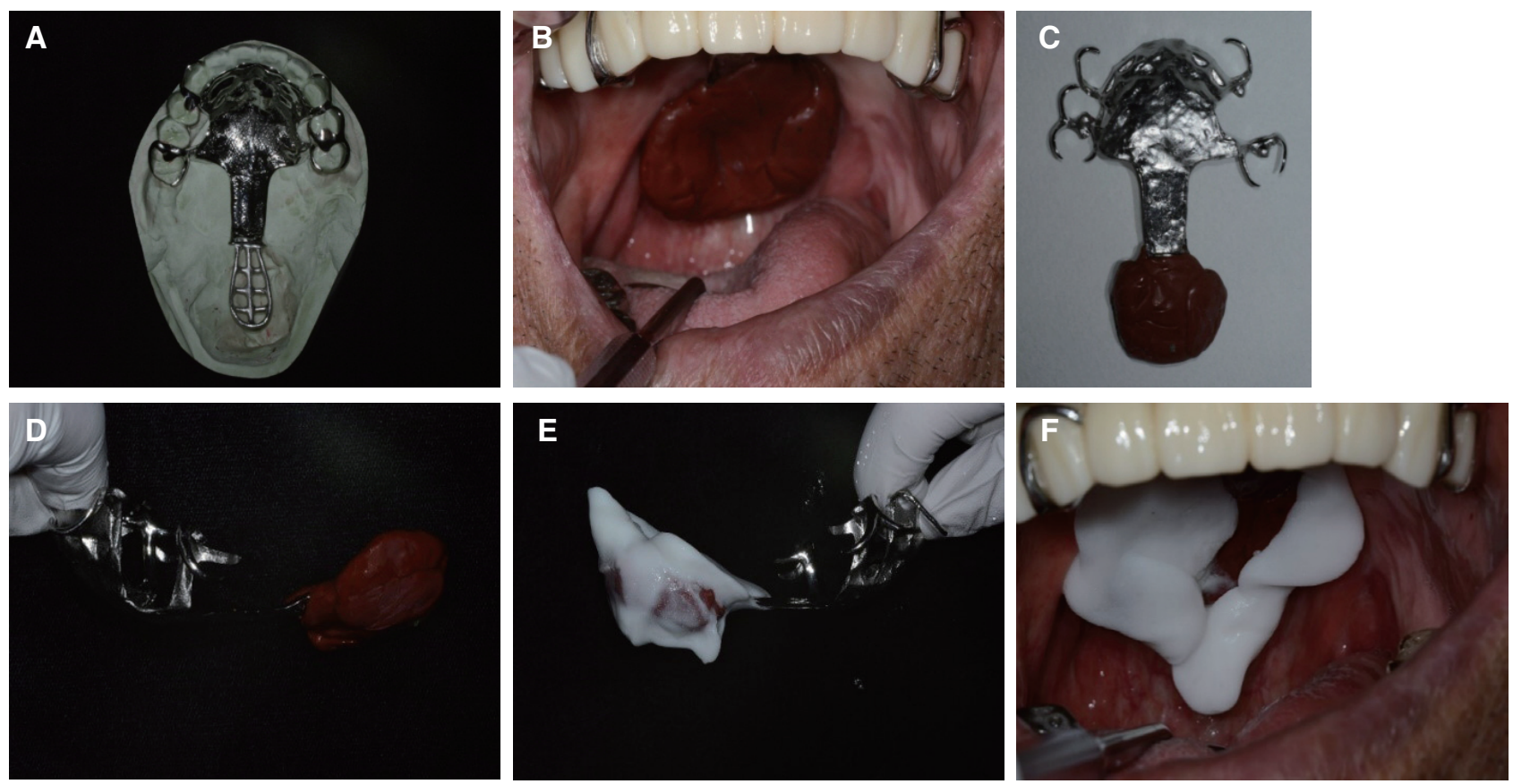

Fig. 7. Bordermolding and Pharyngeal obturator final impression. (A) Metal framework, (B, C, D) Functional impression for pharyngeal part, (E, F) Bordermolding.
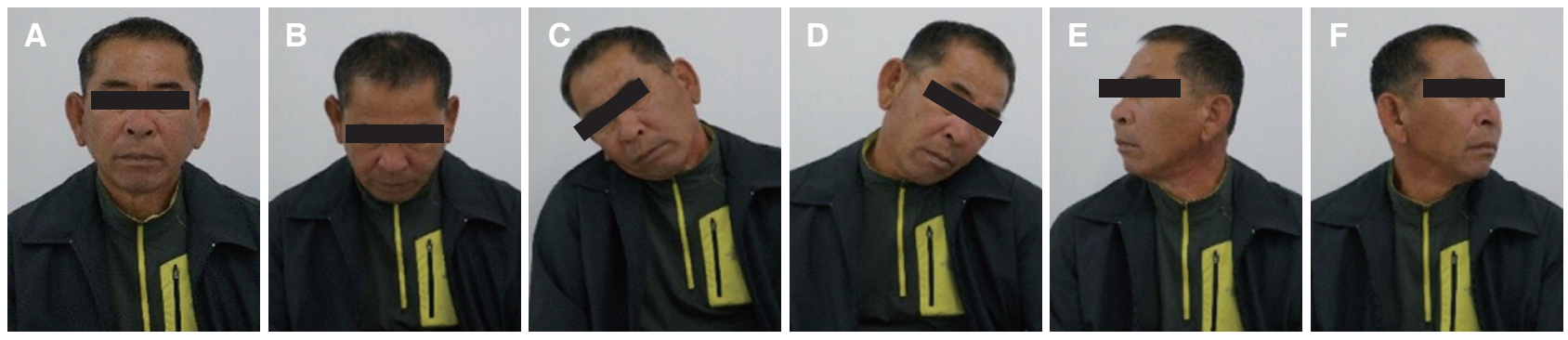

Fig. 8. Flexion and lateral movement. (A, B) Flexion the neck, $(C, D)$ Lateral movement, $(E, F)$ Rotation the neck. 

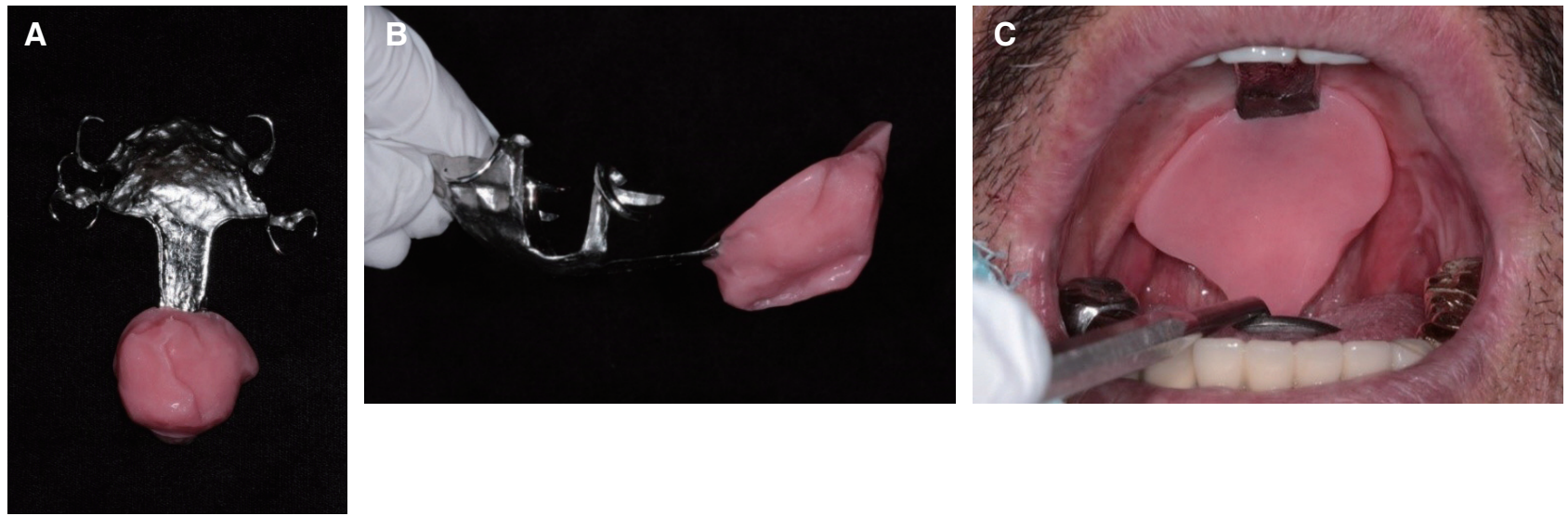

Fig. 9. Definitive pharyngeal obturator. (A) Lingual view, (B) Lateral view, (C) Intraoral view.
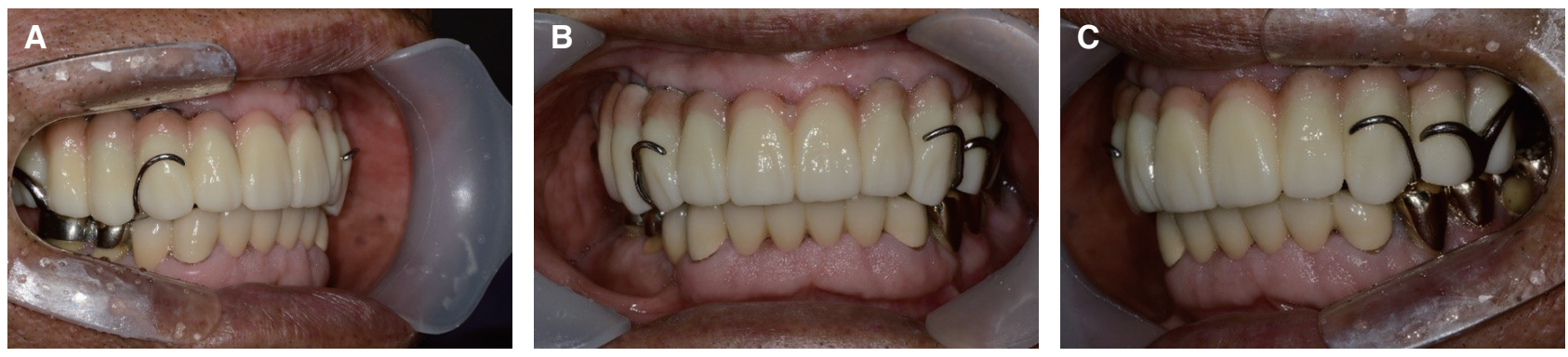

Fig. 10. Definitive restoration. (A) Right lateral view, (B) Frontal view, (C) Left lateral view.

치가 완성되었다(Fig. 9, 10).

장치를 장착하고 난 후 1 주일 뒤에 환자의 발음과 연 하, 기능상의 문제점은 없는 지 등을 평가하였다. 인두부 에 연장된 부분을 약간씩 조절하였지만 첨상은 시행하지 않았다. 환자는 폐쇄 보철장치의 유지력, 편리성, 저작 능 력, 그리고 발성 능력에 대해 임시장치에 비해 크게 만족 했다.

\section{고찰}

상악 결손부위는 양성이나 악성 암종의 수술적 절제로 인하여 생성된다. 결손부위의 크기는 다양하며 경구개, 연구개, 치조제, 비강저 등을 포함할 수 있다. ${ }^{6}$ 상악 결손 부는 보철적으로 재건되어야 하는데, 폐쇄장치를 통하여 저작, 발음, 연하, 그리고 심미와 같은 구강의 기능을 회 복 할 수 있다. ${ }^{2}$ 폐쇄장치의 지지와 유지는 잔존치, 치조 제, 잔존 경구개에서 얻을 수 있다. 또한 수술 후 발생한
결손부위를 폐쇄하여 비강과 구강 사이를 분리한다. ${ }^{7,8}$

잔존 치아는 폐쇄장치의 유지에 가장 큰 역할을 하고 잔존치의 위치, 수, 치주상태가 잔존치의 유지력을 결정 할 수 있다. ${ }^{9}$ 본 환자의 잔존치는 치은연하 우식이 진행되 어있고, 치주 상태 또한 지대치로 사용하기에 불량하였 다. 또한 치관 대 치근비가 좋지 않아 잔존치를 모두 발 거하고 폐쇄장치의 지대치로서의 기능을 위해 고정성 임 플란트 보철을 시행하였다.

본 증례에서는 상악에 임플란트를 이용한 고정성 보철 물로 우측은 제 1 대구치, 좌측은 제 2 소구치까지 잔존치 아를 형성하였으나 후방 인두부의 결손부위가 매우 광범 위하였다. 의치의 유지 및 지지를 증가시키고 응력을 분 산시키기 위하여 가능하면 많은 치아를 지대치로 사용하 였다. 주 연결장치는 구개판형을 사용하여 구개의 해부 학적인 외형을 따름으로서 주조물의 균일한 두께를 부여 하고 얇은 금속판 형태로 혀에 편안한 느낌을 주었다.

클라스프는 wrought wire, embrasure clasp, Akers 
clasp를 이용하여 최대의 유지를 얻고자 하였고 클라스 프는 교합시 대합치와 접촉하지 않게 하였다. 가능한 많 은 치아에 직접유지장치와 간접유지장치를 이용하여 스 트레스를 넓게 분산시키는 것이 중요하다. ${ }^{10}$ 임플란트의 장축방향으로 부하를 전달하고 정교한 지지를 얻기 위하 여 교합면 레스트, 설면 레스트를 형성하고 레스트시트 를 충분히 확장시켜 폐쇄장치의 위치를 지지하면서 조직 방향으로의 움직임을 방지하며 연조직이 눌리는 것을 방 지하였다.

본 증례의 환자는 수술 시 결손부위의 좌측 연구개가 후방까지 제거되어 폐쇄장치를 비 인두까지 연장하여 변 연 폐쇄를 확보하였다. 개인트레이를 이용하여 기능인상 후 인상 채득한 모형으로 금속구조물을 제작한 뒤 금속 구조물을 기반으로 다시 결손부위를 정밀 인상 채득하였 다. 금속구조물은 후방부위의 무게를 견디고 금속구조 물의 파절에 저항하기 위해 얇지만 폭이 다소 넓게 제작 하였다. 후방 결손부위는 케 타입 컴파운드로 대략적인 인상을 채득한 후 점막조정제로 기능운동하여 정밀인상 을 채득하였다. 결과적으로 결손 부위의 측벽에서 충분 한 유지를 얻고 인두 후방부위가 적절히 폐쇄될 수 있도 록 하였다.

환자가 최종적으로 상악 폐쇄장치를 장착한 후 기능적 으로 우선 만족하였고, 장치를 끼고 있지 않을 때에도 지 르코니아 금관으로 인하여 심미성을 얻을 수 있었다. 환 자의 저작, 발음, 연하 기능에 큰 개선과 함께 현재 1 년간 의 추적조사를 진행하고 있다. 임플란트 부위는 골 흡수 나 치은 염증 등의 문제점을 보이지는 않았다. 앞으로 주 기적인 내원 지도하여 임플란트 부위의 점검과 함께 필요 하다면 후방 인두부에 첨상을 시행할 예정이다.

\section{결론}

본 증례는 선양낭포암으로 인해 좌측 상악구치부에서 비인두에 이르기까지 상악골부분절제술을 시행한 환자에 서 전악 고정성 임플란트를 이용한 인두폐쇄장치를 제작 하여 저작, 발음, 연하 기능을 회복하고 심미적인 부분에 서도 만족스러운 결과를 얻었기에 이를 보고하고자 한다.

\section{ORCID}

Min-Hee Ban http://orcid.org/0000-0003-3231-0591

Hong-So Yang http://orcid.org/0000-0002-9138-4817
Sang-Won Park http://orcid.org/0000-0002-9376-9104

Hyun-Pil Lim http://orcid.org/0000-0001-5586-1404

Kwi-Dug Yun http://orcid.org/0000-0002-2965-3967

Chan Park http://orcid.org/0000-0001-5729-5127

\section{References}

1. Spiro RH, Huvos AG, Strong EW. Adenoid cystic carcinoma of salivary origin. A clinicopathologic study of 242 cases. Am J Surg 1974;128:512-20.

2. Haralur SB, Shah FK. Prosthetic rehabilitation of a patient with adenoid cystic carcinoma with continuous orbital-maxillary defect. BMJ Case Rep 2013 Apr 18;2013. pii: bcr2013009313. doi: 10.1136/bcr2013-009313.

3. Brown KE. Clinical considerations improving obturator treatment. J Prosthet Dent 1970;24:461-6.

4. Brown KE. Peripheral consideration in improving obturator retention. J Prosthet Dent 1968;20:17681.

5. Eckert SE, Desjardins RP, Taylor TD. Clinical maxillofacial prosthetics. 1st ed. Chicago; Quintessence publishing; 2000. p. 125-31.

6. Keyf F. Obturator prostheses for hemimaxillectomy patients. J Oral Rehabil 2001;28:821-9.

7. Esposito SJ, Rieger J, Beumer J. Rehabilitation of soft palate defects. In: Beumer J, Marunick MT, Esposito SJ. Maxillofacial rehabilitation: prosthodontic and surgical management of cancer-related, acquired, and congenital defects of the head and neck. 3rd ed. Chicago; Quintessence Publishing; 2011. p. 213.

8. Ackerman AJ. The prosthetic management of oral and facial defects following cancer surgery. J Prosthet Dent 1955;5:413-32.

9. Desjardins RP. Obturator prosthesis design for acquired maxillary defects. J Prosthet Dent 1978;39: 424-35

10. Kaires AK. Effect of partial denture design on bilateral force distribution. J Prosthet Dent 1956;6: 373-85. 


\section{선양낭포암 환자에서 전악 고정성 임플란트와 인두 폐쇄장치를 이용한 악안면 수복증례}

반민희, 양홍서, 박상원, 임현필*, 윤귀덕, 박 찬, 신진호

전남대학교 치의학전문대학원 보철학교실

상악절제술 후 환자들의 재건 치료는 쉽지 않은 과정이다. 상악골 결손은 저작, 발음, 연하 장애를 초래하여 기능적인 회 복이 필요하다. 폐쇄장치 제작의 목표는 결손부를 대체하여 구강기능을 회복하고 환자에게 편안함과 심미성을 제공하는 것이다. 본 증례에서는 임플란트를 이용한 인두 폐쇄장치 제작 후 획득한 저작력과 심미성 그리고 개선된 유지력을 보고 하고자 한다.

(구강회복응용과학지 2016;32 (4):351-7)

주요어: 선양낭포암; 상악절제술; 인두 폐쇄장치; $\mathrm{CAD} / \mathrm{CAM}$ 